\title{
Identifikasi dan Perancangan Pengendali PID Menggunakan Penduga ARX Sistem Pemanas Udara
}

\author{
Ainie Khuriati RS \\ Jurusan Fisika, Fakultas Sains dan Matematika, Universitas Diponegoro. \\ Jl. Prof Sudarto SH, Kampus Tembalang, Semarang \\ khuriati@yahoo.com, ainie_khuriati@undip.ac.id
}

\begin{abstract}
Abstrak - Pada makalah ini digunakan metodologi estimasi Auto-Regression model with eXogeneous inputs (ARX) untuk merancang pengendali PID yang digunakan untuk mengendalikan suhu pemanas udara. Masukan tangga dikenakan terhadap system pemanas dan data suhu udara dikirim ke MATLAB melalui system akuisisi data. Data yang diperoleh digunakan untuk mengidentifikasi model proses dalam bentuk ARX. Parameter PID diperoleh dengan meminimalkan integral galat (IAE, ISE, ITSE, dan ITAE,).
\end{abstract}

Kata kunci: Pengendali PID, Penalaan, Identifikasi, Integral Galat, $\quad$ dan sistem pemanas

Abstract - In this paper ARX estimation methodology used to design a PID controller for temperature control of the air heater. The step input applied on heating systems and logging the data to MATLAB via a data acquisition system. The data obtained is used to identify the model of the process in the form of ARX estimator. PID parameters obtained by minimising the standard errors integral (IAE, ISE, ITSE and ITAE).

Key words: PID controller, Tuning, ARX Identication, Error Integral , and air heater

\section{PENDAHULUAN}

Hampir 90\% indutri yang bergerak di bidang proses menggunakan PID sebagai pengendali [18], hal ini tidak hanya disebabkan strukturnya yang sederhana (hanya mempunyai tiga parameter yang perlu ditala), namun juga secara konseptual mudah dipahami. Karena itu. memungkinkan menala parameter-parameternya secara manual. Selain itu algoritma PID telah menunjukkan kinerja yang relatif memuaskan dalam sebagian besar penggunaannya [3].

Terdapat sejumlah metode penalaan dan selama beberapa tahun terakhir banyak upaya penelitian yang telah dilakukan untuk perbaikan, baik dalam kekokohan dan penolakan terhadap gangguan seperti yang telah dilakukan oleh [3][5] [13][17][18][19]. Fungsi alih pengendali PID ideal dituliskan dalam bentuk transformasi Laplace,

(1)

$$
K=K_{c}\left(1+\frac{1}{T_{i} S}+T_{d} s\right)
$$

Fungsi alih pada pers. (1) tidak tepat dan tidak dapat digunakan dalam praktek, karena meningkatnya bati juga diikuti meningkatnya frekuensi [19]. Oleh karena itu pada pengendali PID praktis dilengkapi dengan penapis orde pertama lolos rendah untuk membatasi frekuensi tinggi., PID praktis memiliki fungsi alih sebagai berikut:
(2)

$$
K=K_{C}\left(1+\frac{1}{T_{i} S}+\frac{T_{d} S}{\frac{T_{d}}{10} S+1}\right)
$$

Teknik penalaan yang paling populer adalah metode Ziegler-Nichols. Namun, selain hanya cocok untuk sistem dengan respon langkah monoton, pengendali PID yang ditala menggunakan metode Ziegler-Nichols umumnya memiliki respon langkah dengan persen overshoot tinggi [16]. Untuk sistem linear, kondisi tersebut dapat diatasi melalui stabilitas margin Keuntungan lain pengendali PID berbasis pada penalaan fase dan gain margin adalah dapat diterapkan pada system orde lebih tinggi [1][6][20]. .

Cara yang paling baik untuk mencari nilai parameterparameter PID yang cocok sebenarnya adalah melalui pemodelan matematika dari system yang akan dikendalikan. Parameter-parameter tersebut dapat dihitung untuk mendapatkan respon yang diinginkan..

Permasalahan utama untuk mendapatkan model matematik dari system adalah kurangnya pengetahuan tentang karakteristik fisis dari system yang diselidiki. Dalam kasus seperti ini model kotak hitam dapat digunakan, model kotak hitam sebuah sistem adalah model yang dibangun tanpa menggunakan pengetahuan tertentu dari karakter atau fisika [12]. Salah model kotak hitam adalah model ARX. Penelitian yang menggunakan model ARX untuk pengendalian suhu dapat dilihat pada [2][10][15]Makalah ini berkaitan dengan model kotak hitam yaitu model ARX 
untuk system dinamis berdasarkan pengukuran masukan dan keluaran.

\section{LANDASAN TEORI}

2.1. Metoda Penalaan untuk Kriteria Integral Galat Minimum

Sistem kendali berumpan balik berperan penting untuk mengurangi galat, $e(t)$ antara setiap variabel dan mencapai nilai nol secepat mungkin. Oleh karena itu, kriteria apapun yang digunakan untuk mengukur kualitas respon sistem harus memperhitungkan variasi $e$ selama rentang seluruh waktu.

Terdapat empat kriteria dasar yang umum digunakan

Integral of squared error

$$
\mathrm{ISE}=\int_{0}^{\infty}\{e(t)\}^{2} d t
$$

Integral of absolute error

$$
\mathrm{IAE}=\int_{0}^{\infty}|e(t)| d t
$$

(4)

Integral of time multiplied by squared error

$$
\operatorname{ITSE}=\int_{0}^{\infty} t\{e(t)\}^{2} d t
$$

Integral of time multiplied by absolute error,

$$
\text { ITAE }=\int_{0}^{\infty} t|e(t)| d t
$$

ISE mengintegrasikan kuadrat kesalahan dari waktu ke waktu. Galat yang kecil saja akan menghasilkan ISE yang besar. Dengan meminimalkan ISE cenderung menghilangkan kesalahan besar dengan cepat, tetapi akan mentolerir kesalahan kecil yang bertahan untuk jangka waktu yang lama,. Respon paling cepat, dengan, amplitudo cukup rendah, tetapi berosilasi.

IAE mengintegrasikan kesalahan mutlak dari waktu ke waktu. Hal ini menghasilkan respon lebih lambat dari sistem ISE optimal, tetapi osilasinya lebih berkurang sehingg lebih cepat teredam.

ITSE memiliki pengali waktu tambahan dari galat fungsi yang menitik beratkan pada lamanya durasi galat, oleh karena itu kriteria ini paling sering diterapkan dalam sistem membutuhkan waktu penetapan yang cepat.

ITAE mengintegrasikan kesalahan mutlak dikalikan dengan waktu dari waktu ke waktu. Galat yang kecil akan menghasilkan ITAE yang besar setelah waktu yang lama. Kelemahan dari tuning ITAE juga menghasilkan overshoot yang paling tinggi

\subsection{Identifikasi system ARX}

Pengetahuan akan model dari system yang diselidiki diperlukan untuk memaham karakteristik dinamik dari system tersebut [4]. Secara teoritik adalah mungkin untuk mengembangkan model system dari pengetahuan mendasar dari proses, akan tetapi dalam prakteknya seringkali terjadi bahwa sistemnya terlalu kompleks untuk bisa memperoleh model yang cukup akurat [10][11]. Seperti halnya proses pemanasan dalam sangkar nyamuk cukup kompleks untuk dapat dimodelkan secara akurat hanya berdasar pada sifat fisisnya, karena secara fisis ruangannya cukup terbuka. Dalam kasus seperti ini model dapat ditentukan secara eksperimental berdasarkan pada hubungan hubungan antara masukan dan keluaran dari sistem ( $\mathrm{K}$. Unklesbay) . Salah satu tujuan dari penelitian ini adalah untuk menemukan model berkaitan dengan tegangan masukan terhadap suhu udara dalam sangkar nyamuk .

Hubungan masukan-keluaran yang paling sederhana diberikan dalam bentuk persamaan diferensi linier [11]:

$$
\begin{aligned}
& y(t)+a_{1} y(t-1)+\cdots+a_{n_{a}} y\left(t-n_{a}\right)= \\
& b_{1} u(t-1)+\cdots+b_{n_{b}}\left(t-n_{b}\right)
\end{aligned}
$$

Pers. (3) disebut sebagai model Auto-Regression model with eXogeneous inputs (ARX) yang dapat dituliskan pula dalam format yang lebih kompak sebagai berikut:

$$
A(q) y(t)=B(q) u(t)+e(t)
$$

Dengan polynomial $A(q)$ dan $B(q)$ diberikan oleh:

$$
\begin{aligned}
& A(q)=1+a_{1} q^{-1}+\cdots+a_{n_{a}} q^{-n_{a}} \\
& B(q)=b_{1} q^{-1}+\cdots+a_{n_{b}} q^{-n_{b}}
\end{aligned}
$$

Diagram kotak struktur model ARX ditunjukkan gambar 1

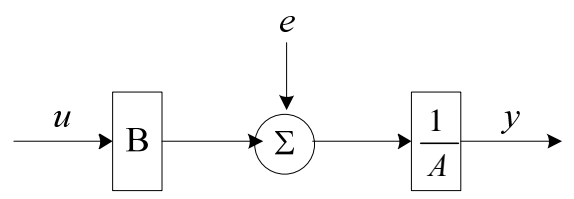

Gambar 1. Diagram kotak struktur model ARX

\section{METODE PENELITIAN/EKSPERIMEN}

\subsection{Identifikasi Sistem}

Identifikasi system adalah menentukan model plan secara eksperimental.

a. Plan

Plan yang digunakan adalah sitem pemanas udara pada sangkar nyamuk yang digunakan untuk penelitian siklus hidup nyamuk demam berdarah. Untuk mendapatkan model, 
pertama plan diberi masukan tangga dan keluaran yang berupa suhu diukur. Obyek data diciptakan dengan menggunakan Matlab system identification toolbox dengan sintaks

$$
\operatorname{Data}=\operatorname{iddata}(y, u, T s) \text {; }
$$

$y$ adalah keluaran (suhu) dan $u$ adalah masukan (tegangan), $T s$ adalah interval pencacahan

b. Struktur model yang dipilih

Parameter model ditentukan menggunakan struktur model ARX sebagaimana didefinisikan disebutkan dalam pers. (3). Model diperoleh dengan menggunakan sintaks:

$$
\text { Model }=\operatorname{arx}\left(\text { data },\left[\begin{array}{lll}
3 & 3 & 1
\end{array}\right]\right) \text {; }
$$

c. Validasi Model

Model yang dihasilkan kemudian divalidasi untuk memastikan bahwa model yang diperoleh cukup akurat. Perintah compare dari identification toolbox digunakan untuk membandingkan antara keluaran eksperimental dengan model yang diestimasi. Perintah,

$$
\text { compare(data,model) }
$$

Prosentase variasi keluaran diberikan oleh model

$$
f i t=100\left(1-\frac{\operatorname{norm}\left(y_{\text {est }}-y\right)}{\operatorname{norm}(y-\bar{y})}\right)
$$

$y_{\text {est }}$ dan $\bar{y}$ masing-masing adalah keluaran model estimasi dan rata-rata dari $y$

\subsection{Penalaan Sistem}

Terdapat berbagai teknik untuk merancang atau menala pengendali PID [14]. Terlepas dari pendekatan yang digunakan, perancangan haruslah kokoh (robust). Kekokohan dapat dicapai melalui minimalisasi gain dan fase margin [6]. Kontroler PID secara tradisional telah dirancang menggunakan pertimbangan gain dan fase margin [1].

Aturan penalaan Ziegler-Nichols memberikan pendekatan praktis untuk menala pengendali PID. Langkah kunci pendekatan untuk menentukan untimate gain $\left(K_{u}\right)$ and period $\left(P_{u}\right)$. Katakanlah model plan yang diperoleh mempunyai gain margin $G_{m}$ dan frekuensi crossover $\omega_{c g}$, ini setara menghubungkan dengan pengendali gain satuan. Oleh karena itu, jika gain pengendali meningkat sebesar Gm, sistem akan berosilasi pada frekuensi $\omega_{c g}$ [20], sehingga,

$$
K_{u}=G_{m}
$$

Dan

$$
P_{u}=\frac{2 \pi}{\omega_{c g}}
$$

Gain margin $G_{m}$, Fase margin $P_{m}$, dan frekuensi crossover $\omega_{c g}$ dihitung dengan menggunakan sintaks dari Matlab Control Toolbox

$$
\left[G_{m}, P_{m}, \omega_{c g}\right]=\operatorname{margin}(\operatorname{model})
$$

Dengan aturan Ziegler Nichols [9], parameter PID diperoleh dengan ,

$\frac{2 K_{u}}{P_{u / 1.7}}$

$\frac{2}{P_{u}}$

$\frac{P_{u}}{8}$

3.3. Minimalisasi kriteria indeks kinerja

$e$ (t) adalah galat yang dihitung sebagai perbedaan antara set point dan keluaran. Sebuah fungsi dari Matlab optimation toolbox (fminuc) dipanggil untuk menghitung minimum dari fungsi kriteria yang diberikan dalam pers (3)(6) .

\section{HASIL DAN PEMBAHASAN}

Gambar 2 diperoleh dari hasil validasi antara keluaran eksperimental dan estimasi model (ditunjukkan oleh garisgaris putus) dengan tingkat kecocokan cukup baik yaitu sebesar 81, 55\%. Kebanyakan aturan penalaan PID didasarkan pada system orde pertama dengan waktu tunda. Dengan menggunakan teknik optimasi modern memungkinkan untuk menala pengendali PID berdasarkan fungsi alih plan nyata untuk mengoptimalkan kinerja loop tertutup [20]. Hasil simulasi dari pengendali PID dengan menggunakan estimasi ARX untuk berbagai jenis kesalahan yang ditampilkan dalam Gbr.4. Hasil simulasi dengan menggunakan metoda Ziegler-Nichols menunjukkan hasil terburuk dibandingkan dengan keempat lainnya, dapat dilihat pada gambar 3 . Kinerja pengendali PID dapat dinilai oleh nilai-nilai parameternya yang dapat dilihat pada tabel 1. Dari tabel 1 dapat dilihat settling time (Ts) paling cepat adalah criteria ISE. Sedangkan criteria ITSE memmpunyai overshoot paling rendah 


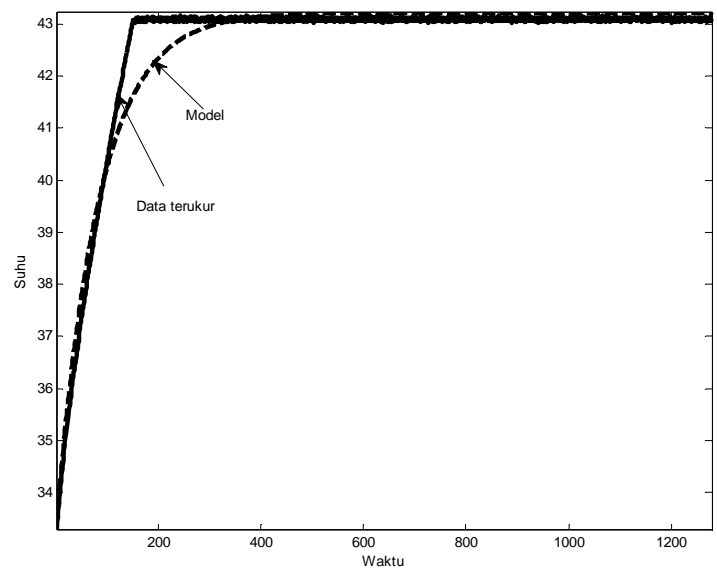

Gambar 2. Perbandingan antara keluaran eksperimental dan model

Tabel 1. Parameter pengendali PID untuk berbagai jenis kriteria

\begin{tabular}{lccccc}
\hline & Z-N & IAE & \multicolumn{1}{c}{ ISE } & \multicolumn{1}{c}{ ITAE } & \multicolumn{1}{c}{ ITSE } \\
\hline$K c$ & 3.3971 & 4,3 & 3,276 & 4,544 & 3,354 \\
$T i$ & 0.9770 & 0,69 & 25,4 & & 61,62 \\
& & & & 1,33 & \\
$T d$ & 0.2442 & 0,37 & & & 0,38 \\
& & & 1,89 & 0,29 & \\
$T r$ & 0,405 & 0,294 & 0,348 & 0,309 & 0,389 \\
$M p$ & $50,6 \%(3)$ & $39,3 \%(0,9)$ & $13,4 \%(0,8)$ & $49,3 \%((1)$ & $10 \%(0,9)$ \\
$T s$ & 4,97 & & & & 3,15 \\
& & 3,97 & 2,89 & 4,06 & \\
\hline
\end{tabular}

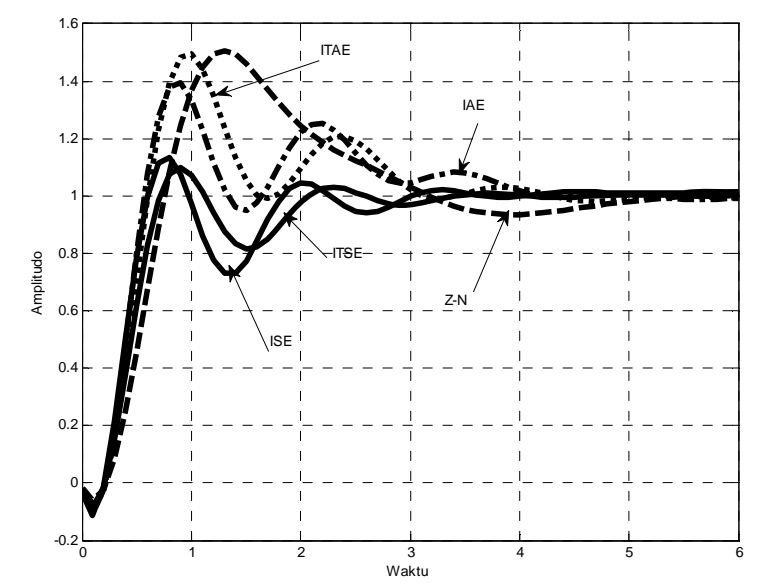

Gambar 3. Perbandingan tanggapan fungsi tangga satuan terhadap plan dengan meminimalkan galat ISE, IAE, ITSE,dan ITAE

\section{KESIMPULAN}

Pengendali PID berbasis pada penalaan fase dan gain margin dapat diterapkan pada system orde ketiga. Dengan meminimalisasi criteria galat, hasil analisis menunjukkan bahwa penalaan plan yang berupa sistem pemanas menunjukkan bahwa criteria ISE menjukkan hasil yang terbaik walaupun memiliki overshoot yang lebih tinggi sedikit dari criteria ITSE. Di lain sisi penalaan dengan metode Z-N memberikan hasil terburuk dibanding dengan lainnya.

\section{UCAPAN TERIMA KASIH}

Ucapan terima kasih saya sampaikan kepada Fakultas Sains dan Matematika Universitas Diponegoro yang telah memberikan dukungan dana untuk melakukan penelitian ini.

\section{PUSTAKA}

[1]. D.l Czarkowski and T. O’Mahony, Intelligent controller design based on gain and phase margin specifications, ISSC Belfast, June 30 - July 22004

[2]. G. Mustafaraja, G. Lowryb, J. Chena, Prediction of room temperature and relative humidity by autoregressive linear and nonlinear neural network models for an open office, Energy and Buildings vol. 43, 2011, pp 1452-1460

[3]. G.P. Liua, S. Daley, Optimal-tuning PID control for industrial systems, Control Engineering Practice vol 9, 2001, pp 11851194.

[4]. H. Chang, P. K.i Tzenog, Analysis of the dynamic characteristics of pressure sensors using ARX system identification, Sensors and Actuators, A 141, 2008, pp 367-375

[5]. H. Pang Huang And C.H. Lin, A Stable On-Line Self-Tuning Optimal Pid Controller For A Class Of Unknown Systems, Asian Journal Of Control, Vol. 9, No. 2, 2007, Pp. 151-162,

[6]. Ho, W. K., C. C. Hang and L. S. Cao (). Tuning of PID controllers based on gain and phase margin specifications. Automatica vol 31(3), 1995, pp 497-502.

[7]. I,D. Landau, System Identification and Control Design Theory for User , Prentice Hall, Englewood Cliffs, NJ, 1990

[8]. J. Kon, Y. Yamashita, T. Tanaka, A. Tashiro, M. Daiguji, Practical application of model identification based on ARX models with transfer functions, Control Engineering Practice, 2012

[9]. J.G. Ziegler, N. B. Nichols, Optimum Settings For Automatic Controllers, ASME, 1942

[10]. K. Unklesbay, A.B. Chacon, and N. Unklesbay, Air temperature transfer function of a convection oven, Food Control, Vol.8, No. 1,, 1997, pp. 39-43

[11]. L.Ljung, System Identification, Theory for the User , Prentice Hall, NJ1999.

[12]. L. Ljung, Black-box Models from Input-output Measurements, IEEE Instrumentation and Measurement, Technology Conference Budapest, Hungary, May 21-23, 2001

[13] P.O Larsson and T. H“agglund, Control Signal Constraints and Filter Order Selection for PI and PID Controllers, 2011 American Control Conference on O'Farrell Street, San Francisco, CA, USA, June 29 - July 01, 2011

[14]. O. D. Aidan, PI and PID controller tuning rules for time delay processes: a summary. Part 2: PID controller tuning rules. Proceedings of the Irish Signals and Systems Conference, National University of Ireland, Galway, June, 1999, pp. 339346

[15]. Q.Bi, W.J. Cai, Q.G Wang,C.C. Hang, E.L. Lee, Y. Sun, K,D Liu Y. Zhang, B. Zou Advanced controller auto-tuning and its application in HVAC, systems Control Engineering Practice vol 8, 2000, 633-644

[16]. R. Bansal, D. Rai, V. Buriah, Design Of Z-N Tuned PID Controller For Higher Order System, 
Http://Www.Aisectuniversity.Ac.In/Anusandhan/8.\%20desig $n \% 20 o f \% 20 z . P d f$, Diakses Tanggal 13-2-2013 Jam 2.47

[17]. S Tavakoli, M. Tavakoli, Optimal Tuning Of PID Controllers for First Order Plus Time Delay, The Fourth International Conference on Control and Automation (ICCA'03), Montreal, Canada, 10-12 June 2003, pp 942- 946.

[18]. S. E. Mansour, G. C. Kember, R. Dubay, B. Robertson, Online optimization of fuzzy-PID control of a thermal process ISA Transactions vol, 44, 2005, pp 305-314

[19]. S. Tavakoli, M. Tavakoli Optimal Tuning Of Pid Controllers For First Order Plus Time Delay Models Using Dimensional Analysis, the Fourth International Conference On Control And Automation (Icca'03), 10-12 June 2003, Montreal, Canada

[20]. Y. Cao, Learning PID Tuning II: Stability Margin, The MathWorks, Inc, 2012, 